\title{
La brecha de género en las pensiones en España y la Unión Europea
}

\section{The gender gap in pensionsin in Spain and the European Union}

\author{
María López-Martínez y Blas Ángel Marín-López \\ Departamento de Economía Aplicada de la Universidad de Murcia, España \\ Departamento de Fundamentos del Análisis Económico de la Universidad \\ de Alicante, España
}

\section{Resumen}

Las pensiones tienen como objetivo asegurar, mediante una retribución de carácter pecuniario, el mantenimiento de un nivel de vida digno en la etapa de retiro. Sin embargo, las de tipo contributivo se ven afectadas por las desigualdades entre hombres y mujeres que se van acumulando a lo largo de la vida laboral, dando como resultado otra inequidad: la brecha de género en las pensiones. Este trabajo pretende identificar los factores que inciden en esta diferencia, motivada por la menor implicación de la mujer en el mercado laboral, que se manifiesta tanto en una menor participación femenina en la fuerza de trabajo como en una elevada presencia de este colectivo en el empleo a tiempo parcial y la consiguiente mayor propensión a la intermitencia en la vida laboral de la mujer.

Palabras clave: Sistema de pensiones, brecha de género, mercado laboral, sostenibilidad financiera, reformas.

\section{Abstract}

The purpose of pensions is to ensure, through pecuniary remuneration, the maintenance of a decent standard of living in the retirement phase. However, those of a contributory nature are affected by the inequalities between men and women that accumulate throughout the working life, resulting in another inequity: the gender gap in pensions. This paper aims to identify the factors that influence this difference, motivated by the lower involvement of women in the labor market, which is manifested in both a lower female participation in the labor force and a high presence of this group in the employment on time partial and consequent greater propensity to intermittence in the working life of women.

Key words: Pension system, gender gap, labour market, financial sustainability, reforms. 


\section{INTRODUCCIÓN}

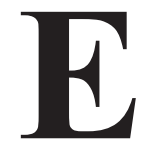

$\mathrm{n}$ la brecha de género de las pensiones inciden factores relacionados con la vida activa en el mercado laboral y, además, existen otros, como la propia configuración del sistema de pensiones. En España, este modelo es de reparto (en cada momento las prestaciones se financian mediante cotizaciones), lográndose así un objetivo importante relacionado con la calidad de vida en la etapa de vejez: reducir el riesgo de pobreza y exclusión social. Sin embargo, la búsqueda de garantizar su sostenibilidad financiera ha propiciado diversas reformas del sistema público de pensiones, algunas de las cuales han afectado de manera más intensa a la mujer (Arcanjo, 2019). Por ello, aunque las pensiones tienen la capacidad de mitigar las inequidades acumuladas durante la vida laboral, en ciertos casos pueden intensificarlas. No obstante, en la última década se ha observado una reducción de la brecha de género en las pensiones, debido al comportamiento favorable de los factores que la causan (Ayuso y Chuliá, 2018).

Aunque la mujer ha tenido hasta hace poco tiempo un papel marginal en el ámbito económico, la lucha por la igualdad de derechos, el cambio en la mentalidad de la sociedad y el avance en su nivel educativo han permitido que se consigan algunos avances, como su creciente incorporación al mercado laboral (Millán-Vázquez, Santos y Pérez, 2015). No obstante, continúan existiendo diferencias por sexo, tanto en la ocupación desempeñada (segregación ocupacional) como en las condiciones laborales (brecha salarial) (Vicente y Martínez, 2010).

Asimismo, estas desigualdades también se plasman en las etapas más avanzadas de la vida de los individuos, a través de las pensiones de jubilación, cuyo objetivo es cubrir ciertas necesidades en un momento en el que suele necesitarse una amplia protección social: la vejez. Además de constituir un mecanismo de ahorro, también tienen el fin de redistribuir la riqueza (Moreno, 1997). Sin embargo, las desigualdades en función del género hacen que la mujer no sólo experimente diferencias en los ingresos actuales, sino que también soporta diferencias en los ingresos futuros, debido al sistema por el que se calculan las pensiones, en función del historial laboral (Vara Miranda, 2013).

Como en muchos países, el modelo de pensiones contributivas español es de reparto, es decir, los cotizantes en un determinado momento contri- 
buyen a pagar las pensiones de ese mismo periodo (contrato intergeneracional implícito) y, además, de prestación definida, lo que implica que el cómputo de la pensión de jubilación depende del salario y de los años de vida laboral de cada trabajador. Esto supone que la cuantía de la pensión de jubilación no depende directamente de la evolución de factores macroeconómicos y sociales relevantes, como, por ejemplo, el envejecimiento demográfico (Devesa, Meneu y Devesa, 2010).

Por otro lado, ante el aumento continuado del gasto en pensiones, se han ido aplicando reformas que buscan la sostenibilidad financiera ${ }^{1}$; medidas que, por lo general, producen pérdidas de poder adquisitivo en los pensionistas, incluso a corto plazo. Además, muchas de las reformas llevadas a cabo afectan de distinta forma a mujeres y hombres, casi siempre en detrimento de las primeras (Vara Miranda, 2011; Arcanjo, 2019).

Las pensiones son, por tanto, uno de los pilares sobre los que se sostiene el Estado de Bienestar y, por ello, es lógico que nos preguntemos en qué medida afectan los factores demográficos, económicos e institucionales, no sólo sobre la sostenibilidad financiera y el gasto en pensiones, sino también en cuestiones sociales como la desigualdad o la calidad de vida de las personas que han salido del mercado laboral y que, en muchos casos, dependen únicamente de las transferencias públicas. Esto nos lleva a plantearnos si la brecha en las pensiones podría estar segregando por sexo algo tan importante como la calidad de vida.

Este trabajo pretende abordar uno de los problemas que surgió incluso antes de la incorporación masiva de la mujer al mercado laboral: la brecha de género en las pensiones. Para ello, se seguirá la siguiente estructura: en primer lugar, necesitamos conocer las características de la población objeto de estudio (factores demográficos), tales como la tasa bruta de natalidad, la esperanza de vida o la estructura y evolución de la población. En segundo lugar, resulta imprescindible profundizar en el origen de esa posible brecha de género en las pensiones: el mercado laboral (factores económicos). Por tanto, conocer cuáles son las causas de la brecha salarial entre hombres y mujeres nos ayudará a entender el origen de la brecha de género en las pensiones. Por último, se hará un breve análisis de las reformas en el sistema de pensiones (factores institucionales) que pueden haber discriminado

\footnotetext{
${ }^{1}$ Esta sostenibilidad del sistema de pensiones depende de factores demográficos (relación entre la población jubilada y la población en edad de trabajar, o tasa de dependencia), económicos, ligados a la situación del mercado laboral (crecimiento económico, tasas de ocupación, paro...) e institucionales (como la relación entre la pensión media y el salario medio, o tasa de sustitución). Hernández, Jimeno y Ramos (2017) explican los factores que han incidido en el cambio de signo del saldo del sistema de la Seguridad Social español, desde un superávit de 2.2 por ciento del PIB en 2007 a un déficit de 1.5 por ciento en 2015 .
} 
también por género y se cuantificará la brecha en las pensiones y su posible efecto sobre la calidad de vida de las personas.

\section{El FACTOR DEMOGRÁFICO}

El estudio de la brecha de género en las pensiones requiere, en primer lugar, conocer las principales características de la población, así como su evolución. Las tendencias de las principales variables demográficas influyen en las pensiones de dos maneras. Por una parte, afectan a los ingresos: el contrato intergeneracional implícito típico de los sistemas de pensiones de reparto implica que los cotizantes soportan el pago de las pensiones con sus cuotas sociales. Sin embargo, dichas cotizaciones dependen del número de cotizantes y, por tanto, de la población ocupada en ese momento, siendo la natalidad y los flujos migratorios condicionantes directos de su evolución. Por otra parte, afectan también a los gastos: el envejecimiento de la población provocado por la disminución de la natalidad y el aumento de la esperanza de vida hace que cada vez sea mayor el gasto público en pensiones. Asimismo, si esto viene acompañado de una reducción de la población que las paga, puede causar graves problemas de sostenibilidad en el sistema.

Algunos expertos en demografía, geografía o sociología, como Dumont (2007), Pérez Díaz (2010) o Serrano-Martínez y García-Marín (2013) consideran el envejecimiento de la población, también llamado "invierno" o atonía demográfica como un proceso irreversible que depende de tres variables: la tasa de fecundidad, la mortalidad y los flujos migratorios. Además, en la disminución de la natalidad ha incidido la creciente incorporación de la mujer al mercado laboral y el acceso a empleos de calidad (Martín López, 2000). Todas estas características nos ayudan a comprender mejor cómo ha evolucionado la población, examinando especialmente si en esta dinámica existen diferencias importantes entre mujeres y hombres.

\section{Evolución de la natalidad}

La natalidad es una de las variables demográficas que pueden influir en las pensiones, dado que si hay menos nacimientos y los flujos migratorios se mantienen constantes, en el futuro habrá una proporción menor de la población disponible para trabajar y, por tanto, que pague cotizaciones, con la consiguiente dificultad en el mantenimiento del sistema de pensiones. 
Figura 1: Tasa bruta de natalidad en España, 1975-2015 (por cada mil)

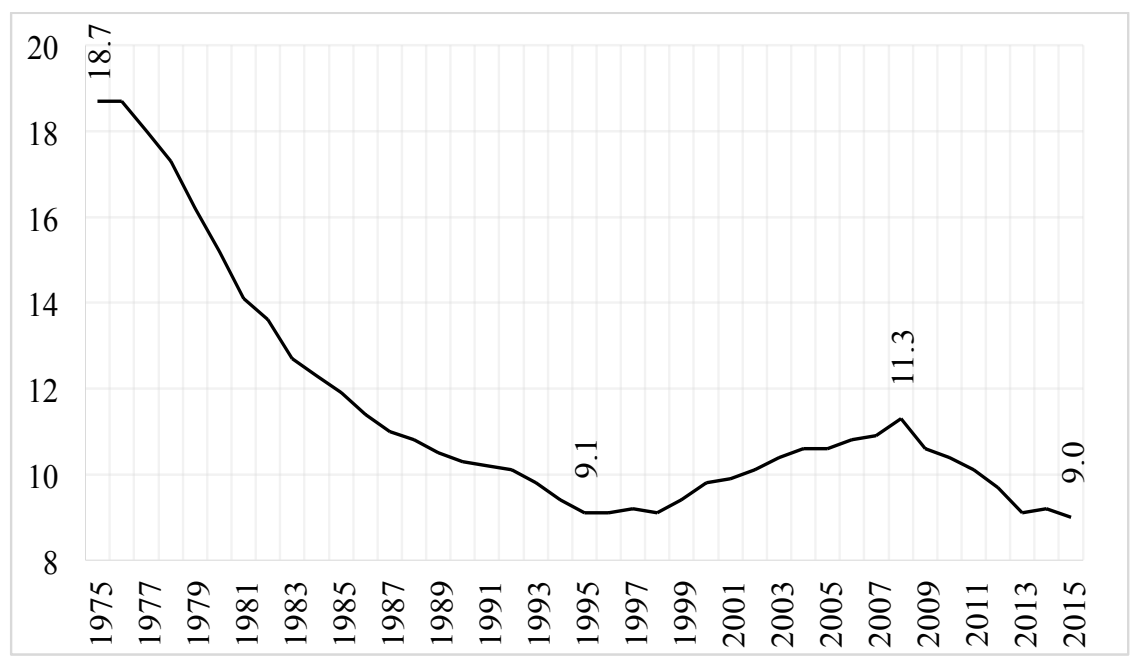

Fuente: elaboración propia a partir de datos de Eurostat, Fertility Stadistics.

Como podemos ver en la Figura 1, la evolución de la tasa bruta de natalidad (media de nacidos por cada mil habitantes) ha tenido una tendencia decreciente, exceptuando algunos años de recuperación que se explican por el comportamiento de la población inmigrante. Se pueden distinguir tres periodos: entre 1975 y 1995, de 1995 a 2008 y a partir de este último año. En el primero de ellos, desde mediados de los setenta a mediados de los noventa, se produce la mayor caída de la natalidad, reduciéndose a más de la mitad (de 18.7 a 9.1 por cada mil), retroceso que se explica, principalmente, por la incorporación masiva de la mujer al mercado laboral. ${ }^{2}$ En la segunda etapa, que coincide con una fase expansiva de la economía española y una masiva llegada de inmigrantes en edad de trabajar, aumenta la natalidad (Jiménez-Ridruejo et al., 2006). No obstante, con el cambio de ciclo posterior se dio una inversión de los flujos migratorios, provocando que la natalidad siguiese su tendencia a disminuir, acabando en 2015 a un nivel parecido al de mediados de los noventa (en torno al nueve por mil cada mil).

\footnotetext{
2 Otros hechos que también han propiciado el descenso de la natalidad son el cambio de valores en la sociedad tras la transición a la democracia, la disminución de la influencia religiosa y el uso más extendido de métodos anticonceptivos, la despenalización del aborto, el retraso en la edad del matrimonio y, en consecuencia, de la edad fértil de la mujer (Del Campo y Rodríguez-Brioso, 2002).
} 
Otra manera de analizar este hecho de forma más específica es mediante la Figura 2, que recoge información sobre la fecundidad y la edad media de maternidad en España.

Figura 2: Índice coyuntural de fecundidad (ICF) y edad media de maternidad (EMM) en España, 1975-2015 (número de hijos y años, respectivamente).

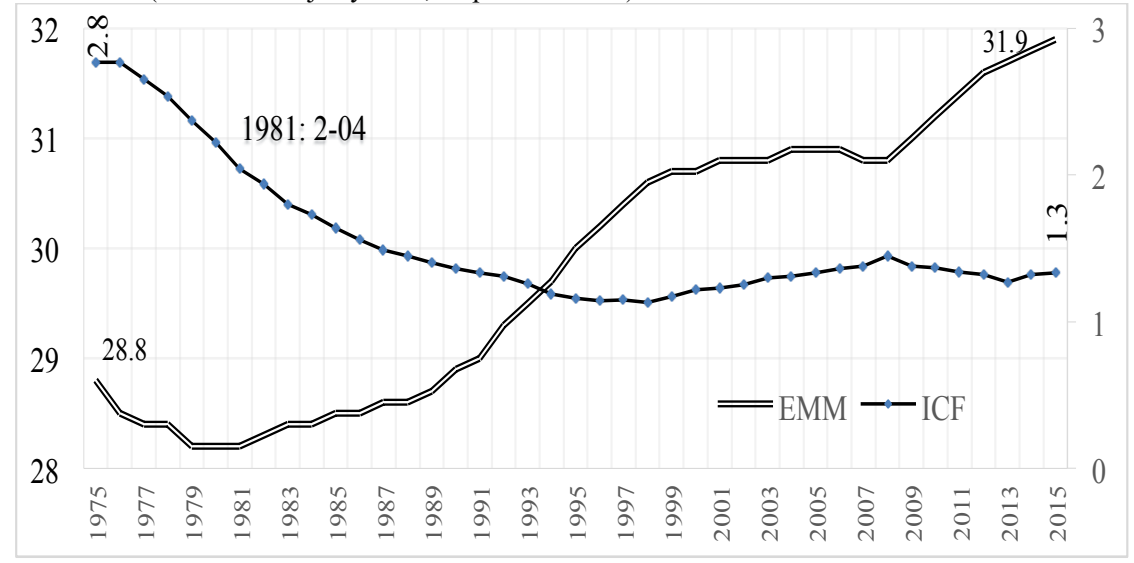

Fuente: elaboración propia a partir de datos de Eurostat, Fertility Stadistics.

Como cabía esperar, el índice coyuntural de fecundidad (ICF) ${ }^{3}$ ha seguido la misma evolución que la descrita por la tasa de natalidad, aunque este indicador ofrece un nuevo resultado: desde el 1981 no se puede asegurar el reemplazo generacional, establecido en 2.1 hijos por mujer, lo cual constituye uno de los factores que provocan el invierno demográfico. Por otra parte, la edad media de maternidad (EMM) ha ido al alza, es decir, cada vez son más las mujeres que deciden posponer la decisión de tener un hijo. Obviamente, existe una relación inversa entre la EMM y el ICF.

Si comparamos estos indicadores con los ofrecidos por Eurostat para la Unión Europea (UE) en 2015, la EMM fue de 30.5 años y el ICF de 1.58, es decir, aunque tampoco se pueda asegurar el reemplazo generacional y sea el continente más envejecido, España supera a la UE en EMM y está por debajo en el ICF, convirtiéndose en uno de los países más afectados por el invierno demográfico (United Nations, 2015).

\section{Evolución de la esperanza de vida}

Otro de los cambios sociales más importantes ha sido el aumento de la esperanza de vida al nacer, tendencia que está condicionada por la mejora

\footnotetext{
3 Definido como el número medio de hijos por mujer en edad fértil, (INE, 2017).
} 
en los hábitos de vida de las personas, así como por un mayor acceso a los servicios sanitarios.

Un hecho característico de esta variable es que las mujeres viven en media más que los hombres (Figura 3), y aunque esta disparidad se ha reducido desde mediados de los noventa, siguen manteniendo un diferencial positivo de 5.5 años actualmente en España. Algunos sociólogos y demógrafos denominan a este hecho feminización de la vejez, puesto que conforme aumenta la edad, el número de mujeres es cada vez mayor (Pérez Díaz, 2003). Este proceso se empieza a notar sobre todo a partir de los 65 años y es un rasgo de la población que se intensificó hasta mediados de los noventa y se ha reducido en las últimas décadas.

Figura 3: Esperanza de vida al nacer según sexo en España, 1975-2015 (años)

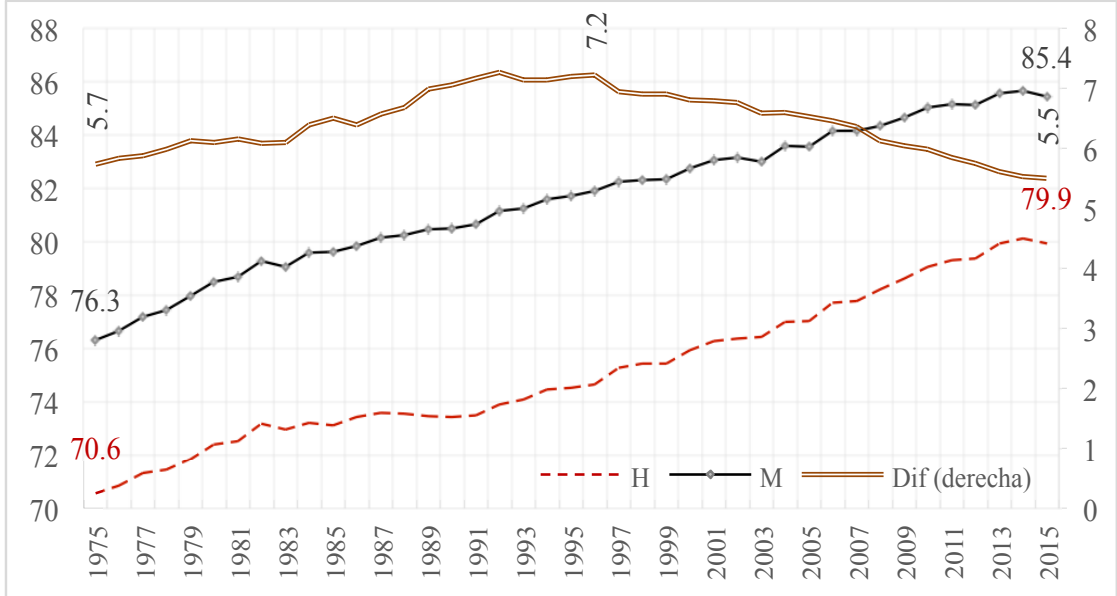

Fuente: elaboración propia a partir de datos del INE, indicadores demográficos básicos.

Así, la población de los países desarrollados está bastante equilibrada por sexos (51 por ciento de mujeres en España según datos del INE), dado que nacen más hombres que mujeres, pero estas últimas viven en media más que los hombres. Sin embargo, cuando se produce una inversión de la pirámide poblacional, el número de nacimientos se encuentra reducido, de modo que acaba habiendo más diferencia entre la población masculina y femenina en detrimento del primer colectivo. Este hecho es importante a la hora de evaluar las pensiones y la calidad de vida de quienes las perciben. Si fuesen las pensiones percibidas por las mujeres mucho menores que las de los hombres, la calidad de vida de las personas en general (y, sobre todo, 
del género femenino), iría empeorando conforme aumenta la edad una vez terminada la vida laboral.

\section{Escenarios futuros: la sostenibilidad del sistema de pensiones}

Uno de los escenarios que más nos preocupa siempre es el futuro y, por ello, son frecuentes las predicciones que nos puedan permitir adoptar soluciones a los problemas previstos. Utilizando las series de la población proyectadas por el INE podemos hacernos una idea de cómo sería la estructura poblacional a largo plazo.

Como se observa en Figura 4, la pirámide poblacional sigue en una transición demográfica hacia la inversión total, perpetuando a España como uno de los países más envejecidos del mundo (United Nations, 2015), lo cual implicaría que el sistema de pensiones de reparto se volvería insostenible y el contrato intergeneracional que supone estaría en riesgo. Según las proyecciones del INE, la población total desde la actualidad hasta 2066 se reduciría 12 por ciento, aproximadamente, salvo que se produzcan variaciones notorias en los flujos migratorios.

En tan sólo medio siglo, según estas proyecciones, los posibles pensionistas $^{4}$ aumentarían 52 por ciento, mientras que la población activa se reduciría 25 por ciento, aproximadamente. Este significativo aumento de la población pensionista se explica, en parte, por las jubilaciones de la llamada generación del baby boom de las décadas de 1960 y 1970 (Lorenzo Carrascosa, 2004; Ayuso y Chuliá, 2018). Sin embargo, como se había reconocido en el Pacto de Toledo firmado en 1995, existen múltiples factores para explicar el avance tanto del número de pensionistas como del gasto en pensiones, además de la dinámica demográfica. Por ejemplo, la mejora de la cobertura del sistema, que ha ido elevando la población protegida; o el llamado efecto sustitución, reflejo de que la cuantía de las nuevas pensiones es mayor que la prestación media de las antiguas (Boletín Oficial de las Cortes Generales,1995).

En el Pacto de Toledo se reconocieron los problemas del sistema de pensiones público y se propusieron diferentes recomendaciones o reformas para paliarlos, como la necesidad de llevar a cabo periódicamente un análisis y seguimiento de la evolución de la Seguridad Social. Asimismo, Vara Miranda (2011 y 2013) apunta que, parte de las reformas del sistema llevadas a cabo en este sentido, han podido afectar de forma más intensa a la mujer.

\footnotetext{
4 Se ha tenido en consideración la reforma del sistema de pensiones del 2011 (Ley 27/2011), por la cual la edad de retiro iría aumentando progresivamente desde 65 hasta 67 años.
} 
La brecha de género en las pensiones en España y la Unión Europea / M. LÓPEZ MARTíNEZ y B.A. MARÍN LÓPEZ

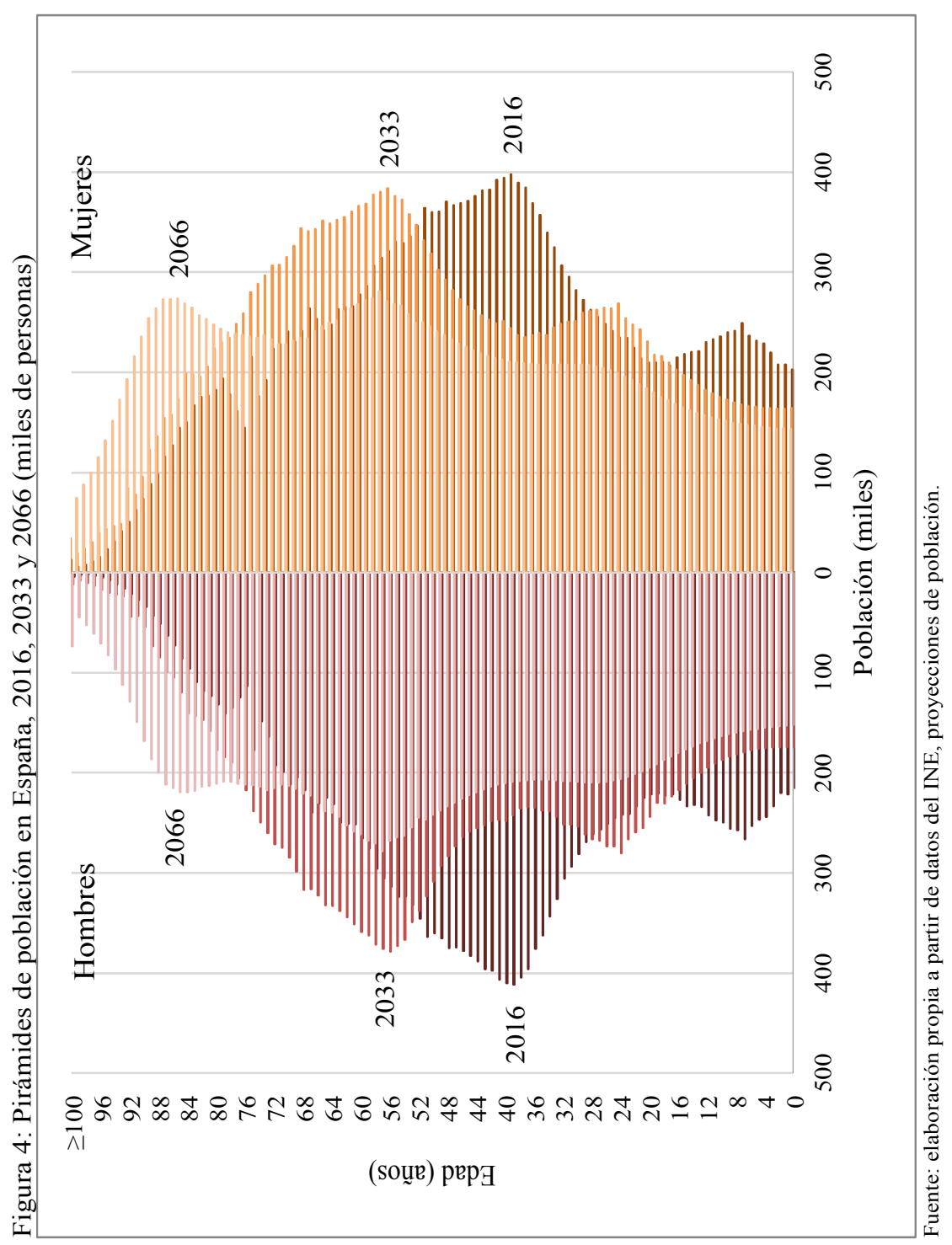


En resumen, el panorama quedaría de la siguiente forma: en primer lugar, cada vez es mayor la esperanza de vida y menor la natalidad, con el consiguiente invierno demográfico, fenómeno que puede verse suavizado mediante los flujos migratorios (Castro Martín, 2010); y, en segundo lugar, la inversión de la pirámide implica que cada vez hay más mujeres que hombres en los escalones superiores, es decir, un mayor número de mujeres pensionistas. Esto último implicaría que, ante la existencia de una brecha en las pensiones por género, se podría generar un empeoramiento de la calidad de vida de los pensionistas en conjunto conforme avanza la edad.

\section{El mercado de trabajo y El impaCto de la Gran RECESIÓN}

La crisis económica y financiera de 2007 ha provocado que los cimientos del Estado del Bienestar se vean alterados. La dificultad para sostener el sistema de pensiones no ha sido causada por el impacto de dicha crisis, conocida como Gran recesión, pero sí ha provocado que muchos países, incluido España, deban realizar diversas reformas en aras de conseguir su sostenibilidad. La recesión ha afectado a los considerados activos (oferta de trabajo) al existir una menor probabilidad de poder mantenerse en el mercado laboral o, en el caso de que ya se encontrasen fuera (población parada), una menor probabilidad de poder volver a trabajar. Asimismo, también ha tenido efectos sobre las personas que han terminado su vida laboral y reciben prestaciones en forma de pensión, ya que las numerosas reformas aplicadas para intentar retrasar el problema de la sostenibilidad financiera del sistema de pensiones pueden acabar mermando el poder adquisitivo del pensionista incluso a corto plazo.

Además de los factores demográficos, el ámbito laboral (componente económico) también determina una gran parte de la brecha de género en las pensiones. Esta desigualdad de ingresos existente en el mercado de trabajo está causada por distintos factores, tales como las condiciones de los contratos de trabajo o las interrupciones en la vida laboral debidas al cuidado de personas dependientes. Las diferencias entre hombres y mujeres repercutirán posteriormente en el cómputo de la pensión (en un sistema de prestación definida se calcula según el historial laboral) y, por tanto, en la futura calidad de vida. Por ello, es necesario cuantificar la brecha de ingresos y ver cuáles son las principales causas que lo provocan.

\section{Participación de la mujer en el mercado de trabajo}

La participación laboral femenina puede ser considerada como la primera causa de las diferencias de ingresos entre sexos. Si bien las mujeres siem- 
pre han estado "trabajando", no todas recibían una remuneración dada su habitual dedicación al cuidado del hogar. Sin embargo, este hecho ha ido cambiando desde hace unas décadas con su incorporación al mundo laboral, proceso que no sólo ha favorecido a la mujer, sino que también ha conllevado una serie de beneficios macroeconómicos, tales como el aumento del PIB per cápita al reducir las disparidades entre sexos en el ámbito laboral (Elborgh-Woytek et al., 2013).

Una forma de medir la representación de la mujer en el mercado de trabajo sería con la proporción de mujeres y hombres ocupados, tal como se muestra en la Figura 5.

Figura 5: Participación por sexos en el mercado laboral en España, 1977-2016 (porcentaje)

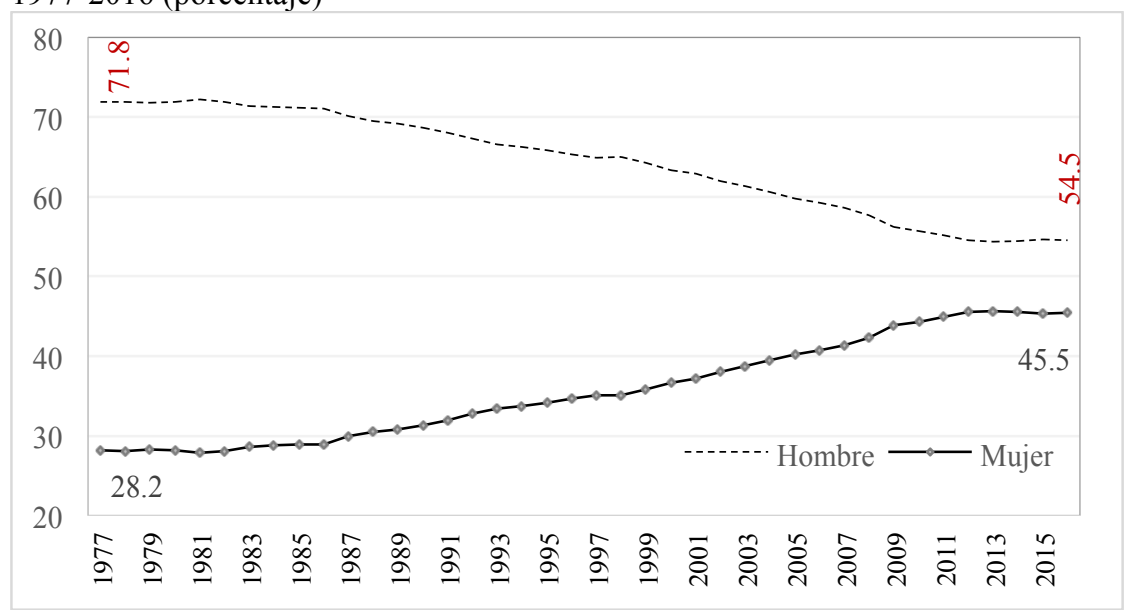

Fuente: elaboración propia a partir de datos del INE, Encuesta de Población Activa (EPA).

Como puede apreciarse, aunque el hombre ha tenido una mayor implicación en el mercado de trabajo que la mujer a lo largo de todo el periodo considerado, existe una clara convergencia en cuanto a la presencia de ambos sexos dentro del empleo. Así, aunque continúan predominando los hombres con 54.5 por ciento de la ocupación en 2015, a mediados de los setenta concentraban 71.8 por ciento del empleo. Esta diferencia, aunque descendente, es una de las causas del diferencial de ingresos entre sexos, el cual ha acabado transmitiéndose sobre las pensiones actuales y continuará haciéndolo en las futuras.

Asimismo, durante la fase de ralentización y crisis económica de 20072013, las diferencias de empleo entre hombres y mujeres siguieron redu- 
ciéndose con mayor rapidez debido a que la crisis afectó especialmente a determinados sectores muy masculinizados, como la construcción.

Otra forma de medir la participación de la mujer es a través de la tasa de actividad, indicador que cuantifica la proporción de población activa (personas que trabajan o buscan activamente un empleo) sobre la población en edad de trabajar, mostrando el grado de implicación en el mercado laboral.

La Figura 6 da cuenta de la tendencia ascendente de la tasa de actividad femenina y descendente la masculina. Esto ha provocado que vaya disminuyendo la diferencia entre ambas, que actualmente se sitúa en 11.5 puntos porcentuales frente a los 48.9 de 1977. Dicha convergencia se explica por los cambios de mentalidad en cuanto a la faceta laboral de la mujer, ligados a su creciente nivel de formación que, además de elevar la empleabilidad de la persona que los posee, también aumenta el coste de oportunidad de permanecer inactivo (Serrano y Soler, 2015).

Figura 6: Tasa de actividad por sexos en España, 1977-2016 (porcentaje)

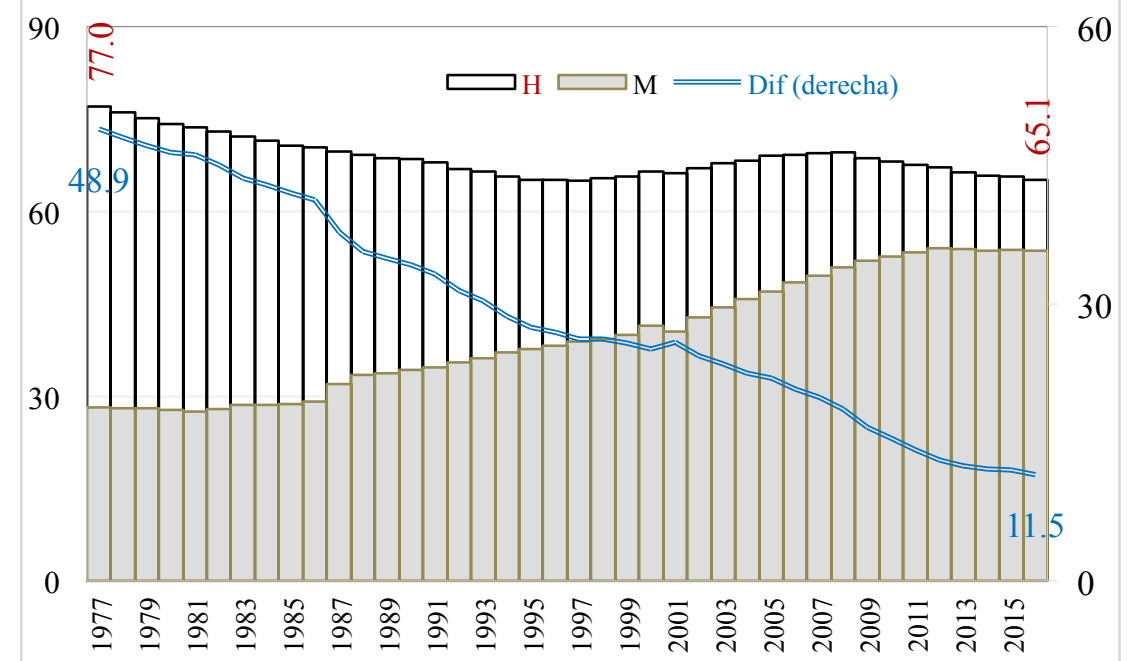

Fuente: elaboración propia a partir de datos del INE, EPA.

\section{El trabajo a tiempo parcial y la conciliación laboral}

Junto con la distinta participación de hombres y mujeres en el mercado laboral, también existen otras causas que inciden en la brecha de género tanto en salarios como en pensiones, entre las que cabe destacar, siguiendo a Bettio, Tinios y Betti (2013), la menor dedicación de la mujer al empleo 
remunerado. Es decir, en la medida en que trabaje un reducido número de horas (por el intenso uso de contratos a tiempo parcial) y durante menos años (debido a las interrupciones a lo largo de la trayectoria laboral, en muchos casos, por el cuidado de personas dependientes), tenderá a cobrar salarios y, por tanto, pensiones más bajas que los varones.

De la Tabla 1 se desprende un hecho estilizado: la feminización del empleo a tiempo parcial, dado que la mujer acaba concentrando alrededor de tres cuartas partes de este tipo de empleo en España. Este es uno de los factores que acaba provocando la brecha salarial pues, aunque los derechos que se adquieren son los mismos con independencia del tipo de jornada, existe una gran diferencia en la remuneración, dado que se gana 43 por ciento ${ }^{5}$ menos por hora en un contrato a tiempo parcial que en uno a tiempo completo.

Tabla 1: Porcentaje de empleo parcial respecto al empleo total por sexo, España y UE-28, 2003, 2007 y 2016

\begin{tabular}{rrrrr}
\hline & España & \multicolumn{2}{c}{ UE-28 } \\
\hline & Hombres & Mujeres & Hombres & Mujeres \\
\hline 2003 & 2.6 & 16.7 & 6.1 & 28.5 \\
2007 & 3.9 & 22.1 & 6.9 & 30.5 \\
2016 & 7.6 & 24.1 & 8.8 & 31.9 \\
\hline
\end{tabular}

Fuente: elaboración propia a partir de datos de Eurostat, Employment Statistics.

Esta feminización del empleo a tiempo parcial es aún mayor en la Unión Europea, lo cual implica que la brecha salarial de la UE será más elevada, ceteris paribus. Por otra parte, cabe destacar que la crisis de 2007 ha aumentado de forma más intensa este tipo de empleo entre los hombres, sobre todo en España, lo que ha permitido acortar la diferencia. No obstante, la mujer sigue recurriendo más a este tipo de empleo por motivos que también son distintos a los del varón, como refleja la Figura 7.

Como puede apreciarse, en 2016, 12.9 por ciento de las mujeres se encuentran empleadas en jornada a tiempo parcial por tener a su cargo el cuidado de personas dependientes (ya sean niños, mayores o enfermos) frente a 1.9 por ciento de los hombres, lo que muestra un reparto desigual de las responsabilidades familiares. Según la Organización Internacional del Trabajo, sigue existiendo una asignación de tareas atribuible a roles estereotipados, lo que provoca que la mujer acabe sacrificando tiempo de

\footnotetext{
${ }^{5}$ Datos obtenidos de la Encuesta de estructura salarial 2014 del INE.
} 
trabajo (vida profesional) por las cargas familiares (Elborgh-Woytek et al., 2013; Valenzuela, Reygadas y Cruces, 2015). No obstante, en los últimos años se ha observado una evolución del reparto de estas cargas favorable debido a la creciente participación del hombre en el ámbito familiar. Así, como queda reflejado en Figura 7, se ha incrementado entre los hombres el porcentaje que están empleados a tiempo parcial principalmente para el cuidado de dependientes (su peso era nulo en 2003 y casi dos por ciento en 2016), avance reseñable pero aún muy alejado de 12.9 por ciento en el colectivo femenino.

Figura 7: Razones del trabajo a tiempo parcial según sexo en España, 2003, 2007 y 2016 (porcentaje)

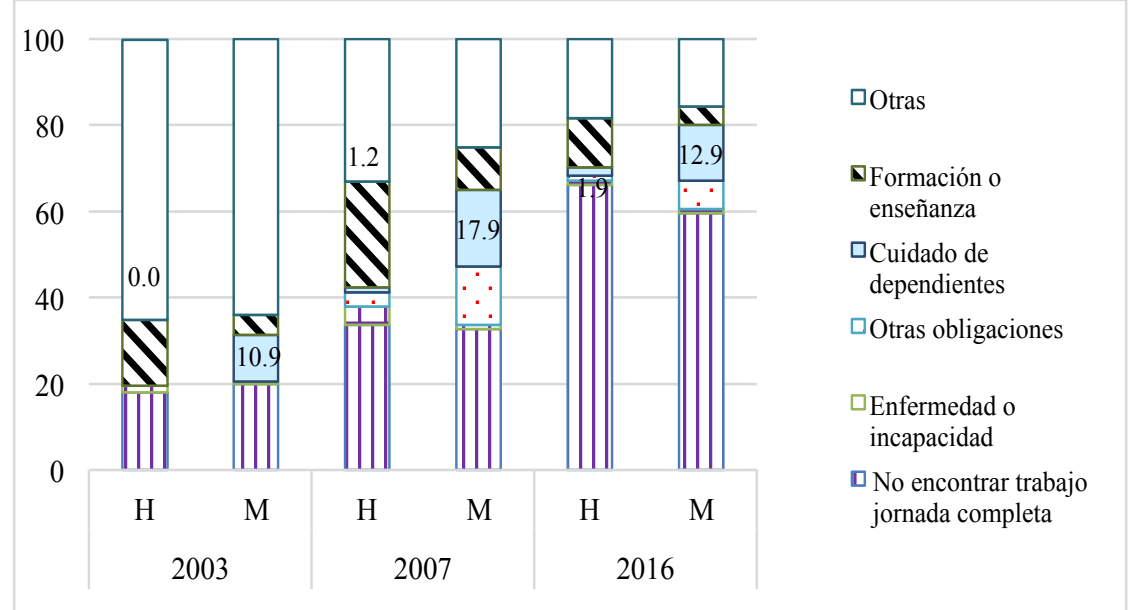

Fuente: elaboración propia a partir de datos de Eurostat, Labour Force Survey.

Como se ha señalado, la mujer participa en trabajos a tiempo parcial en mayor medida que el hombre y, teniendo en cuenta que este tipo de jornada implica un menor número de horas trabajadas, afectará sobre la brecha de ingresos. Además, otro factor que también influirá en la diferencia en las pensiones por género es el número de años trabajados. Eurostat presenta un indicador que nos sirve para reflejar este componente: la duración de la vida laboral, ${ }^{6}$ que mide el número medio de años que se espera que una persona esté activa en el mercado laboral a lo largo de su vida.

Observando la Tabla 2 puede apreciarse que en España la vida activa esperada es muy superior para el hombre (37.2 años frente a los 32.5 de la mujer), lo que implica que el colectivo femenino dedicará menos años

\footnotetext{
${ }^{6}$ Forma parte de los indicadores para medir el progreso de los Objetivos Europa 2020.
} 
a trabajar o a buscar activamente un empleo. En comparación con la UE, se observa una evolución positiva de este indicador más intensa para las mujeres desde 2002 hasta 2015, reduciéndose esta brecha de 11.5 a 4.7 años, diferencial que en la UE pasa de 7.6 a 5.1 años en el mismo periodo.

Tabla 2: Duración de la vida laboral en España y en la UE-28 por sexos, 2003, 2007 y 2015 (porcentaje)

\begin{tabular}{lcccc}
\hline & \multicolumn{2}{c}{ España } & \multicolumn{2}{c}{ UE-28 } \\
\hline 2003 & Hombres & Mujeres & Hombres & Mujeres \\
2007 & 37.2 & 25.7 & 36.4 & 29.8 \\
2015 & 38.1 & 29.0 & 37.1 & 30.8 \\
\hline
\end{tabular}

Fuente: elaboración propia a partir de datos de Eurostat, Employment Statistics.

Sin embargo, estos datos cuentan con una limitación, ya que no se puede saber de forma precisa cuántos años son los trabajados por cada sexo, información que resulta imprescindible, pues acaba siendo una causa directa de la brecha de género en las pensiones. Para soslayar esta limitación, recurriremos a las estimaciones de Bettio, Tinios y Betti (2013), que cuantifican que la mujer trabaja 12.8 años de media frente a los 43.4 del hombre, es decir, existe un diferencial de más de 30 años trabajados. No obstante, si la estimación se ajusta para personas con el mismo tipo de empleo, esta brecha disminuye a 22 años.

Aunque existen diferencias importantes en la brecha estimada según se ajuste o no la serie, cabe destacar que está mostrando la existencia de un gran número de mujeres que nunca han llegado a entrar al mercado laboral o lo han hecho durante un periodo muy corto y, por tanto, únicamente podrán optar a pensiones no contributivas o contributivas derivadas como la de viudez, cuyo importe suele ser menor. Cabe esperar que algunas de las reformas del sistema de pensiones actuales, como el aumento del periodo de cotización o el retraso de la edad de jubilación puedan tener un efecto positivo en la mujer, incentivándola a acceder y permanecer en el mercado laboral.

\section{La brecha salarial por razón de género}

En 2015 la brecha salarial ${ }^{7}$ para España fue de 14.9 por ciento, lo que significa que la mujer cobró, por hora de salario, este porcentaje menos

\footnotetext{
7 Según la definición de Eurostat, la brecha de género es la diferencia entre el salario bruto por hora masculino y femenino, expresado como porcentaje del primero.
} 
que el hombre, cifra que se encuentra por debajo de la media de la Unión Europea, donde alcanza 16.3 por ciento (Tabla 3 ).

Resulta reseñable que países del centro y norte de Europa, como Austria, Alemania Estonia, la República Checa y Reino Unido, tengan una brecha salarial superior a 20 por ciento, lo que puede estar relacionado con uno de los factores que hemos identificado como causantes de la brecha salarial: el empleo a tiempo parcial, dado que una proporción elevada de las mujeres que trabajan en estos países lo hacen con este tipo de jornada, aunque otros países nórdicos, como Suecia, Holanda o Dinamarca utilizan este contrato de forma intensa sin tener una brecha salarial elevada.

Otro caso destacable es el de Italia, Luxemburgo y Rumanía, países cuya brecha salarial no llega a seis por ciento. Para Sarasola et al. (2012), la reducida disparidad de ingresos entre hombres y mujeres en el caso de Italia está ligada con una ley de 1991 que exige a las empresas de más de 100 empleados ofrecer información estadística desagregada por sexos, datos que se ponen a disposición de los sindicatos. Este hecho podría servir para justificar la acción de determinadas normas e instituciones públicas en cuestiones de igualdad, ayudando a paliar el efecto de la brecha de género sobre los ingresos, tanto presentes como futuros.

La Figura 8 da cuenta de las disparidades que existen en la brecha salarial entre hombres y mujeres por edades. Como podemos observar, esta brecha crece de forma exponencial a medida que pasamos de un grupo etario a otro, empezando con una diferencia salarial de 5.7 por ciento para los jóvenes menores de 25 años y acabando en 45.3 por ciento para el grupo de avanzada edad (mayores de 65). Este considerable incremento puede estar ligado a la maternidad, dado que, en los dos primeros grupos de edad, es decir, aquellos que están por debajo o ligeramente por encima de la edad media de maternidad (EMM), apenas se eleva la brecha salarial al cambiar de grupo etario ( 0.9 puntos porcentuales). Sin embargo, una vez superada esta barrera las diferencias salariales casi se van doblando en los dos siguientes estratos. Dejando al margen la elevada brecha del grupo de edad más avanzada, que puede ser poco significativo, puede apreciarse que entre los dos anteriores, cuando las cargas familiares por maternidad son menos frecuentes, la brecha sólo crece algo más de dos puntos. 
La brecha de género en las pensiones en España y la Unión Europea / M. LÓPEZ MARTíNEZ y B.A. MARÍN LÓPEZ

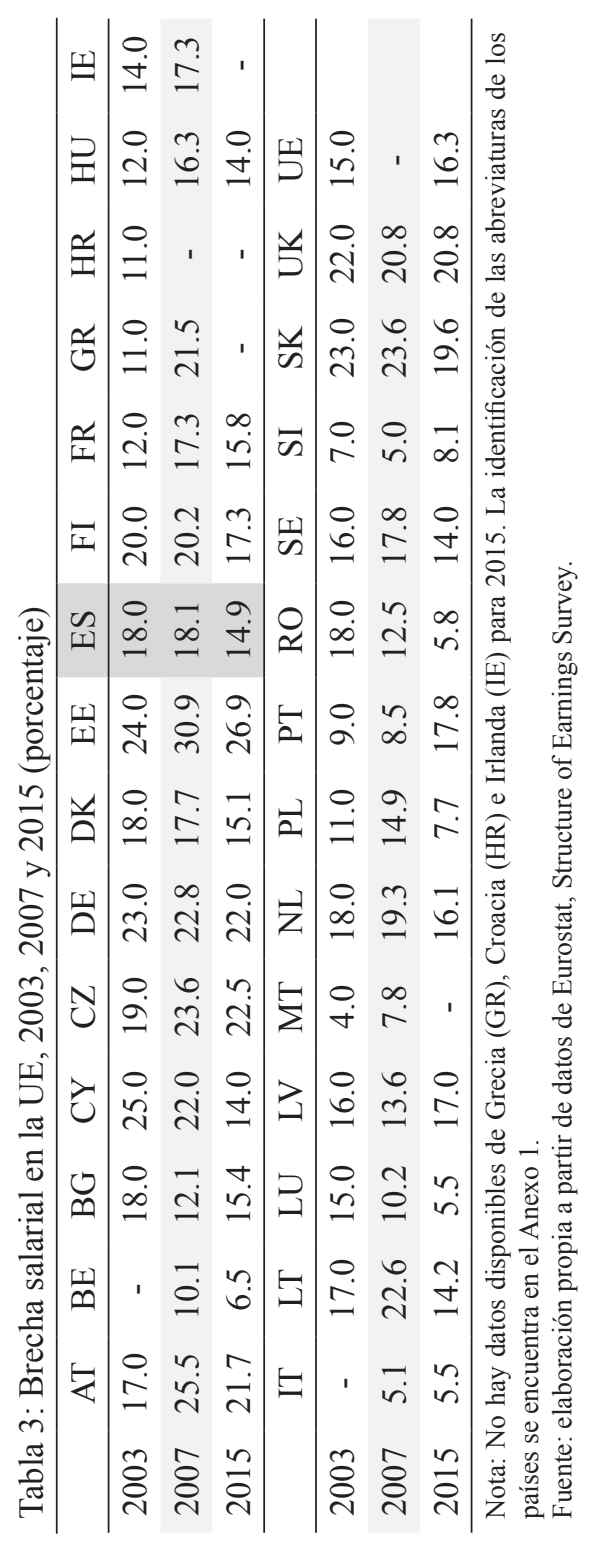


Figura 8: Distribución de brecha salarial por edades en España, 2014 (porcentaje)

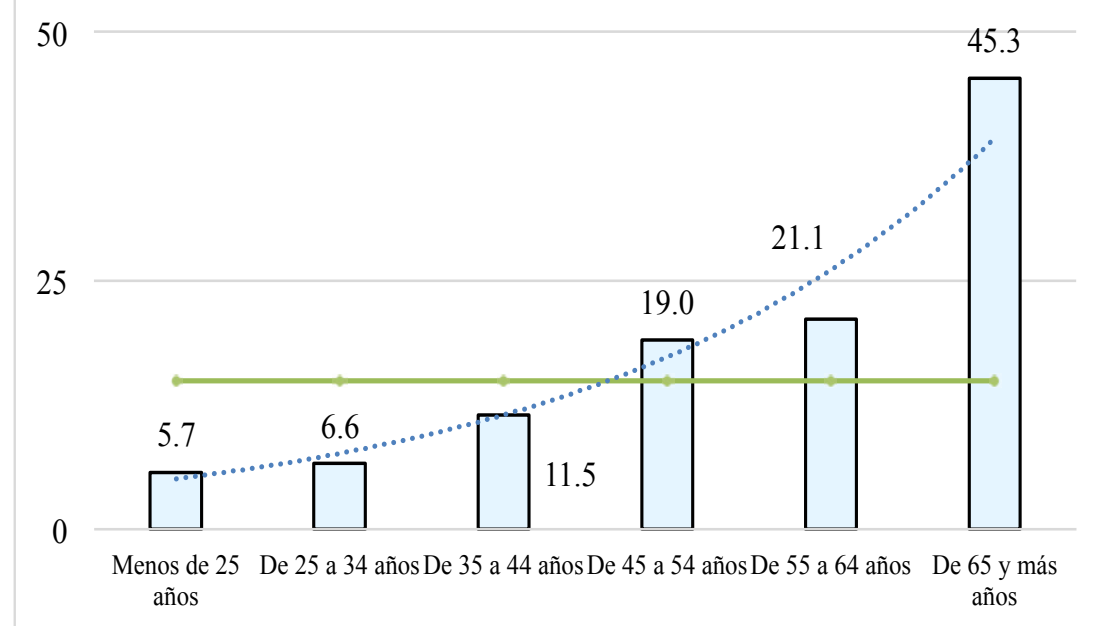

Nota: estos datos son los últimos disponibles, pues la encuesta utilizada es de frecuencia cuatrienal. Fuente: elaboración propia a partir de datos de Eurostat, Structure of Earnings Survey.

\section{EL SISTEMA DE PENSIONES}

Los sistemas de pensiones constituyen un pilar básico del Estado del Bienestar, cuyo objetivo principal es proteger a las personas de edad avanzada, mediante la transferencia de un ingreso suficiente una vez acabada su vida laboral. Sin embargo, las inequidades entre hombres y mujeres producidas en el mercado de trabajo y en el ámbito del hogar, así como las reformas que se producen en el diseño de los sistemas de pensiones (factores institucionales), acaban traduciéndose en una desigualdad de ingresos: la brecha de género en las pensiones.

Una vez examinadas las principales causas de esta brecha, localizadas en el mercado de trabajo, vamos a centrarnos en las correspondientes al propio sistema de pensiones, cuyo diseño puede permitir amplificar o disminuir los efectos de la acumulación de desigualdades durante la vida laboral. Dado que la mujer recibe una transferencia menor que el varón cuando termina su vida laboral, unido a la mencionada feminización de la vejez, podría producirse un aumento del riesgo de pobreza conforme avanza la edad. Por ello, es importante realizar un análisis de los efectos que tienen los cambios normativos en el sistema de pensiones. 


\section{Reformas del sistema de pensiones}

En la década de los noventa se llevaron a cabo modificaciones en el sistema de pensiones en la mayoría de los países europeos, argumentando que era necesario hacer frente al problema de sostenibilidad del mismo, provocado por el envejecimiento de la población. Así se puso de manifiesto en España a mediados de los noventa con la firma del Pacto de Toledo, pero la llegada de la crisis de 2007 añadió nuevas presiones, obligando a los países a retomar medidas de reforma en materia de pensiones (Samek Lodovici et al., 2016; Arcanjo, 2019).

Estas medidas pueden ser agrupadas en dos grandes bloques: reformas estructurales y paramétricas. El primer tipo, como su nombre indica, afectan a la propia estructura del sistema, en nuestro caso, de reparto. Serían reformas de este tipo la creación de cuentas nocionales ${ }^{8} \mathrm{o}$ el paso a un sistema de capitalización. ${ }^{9}$ Por su parte, las reformas denominadas paramétricas alteran las variables que afectan a los ingresos y a los gastos del sistema de la Seguridad Social y, en las últimas décadas, se han utilizado principalmente para contener el gasto en pensiones y poder así mantener el sistema. Algunas de ellas han tenido un efecto casi inmediato sobre el poder adquisitivo de los pensionistas, como dejar de revalorizar las pensiones en función de la inflación prevista, estableciendo en su lugar un índice de revalorización, ${ }^{10} \mathrm{y}$ otras lo harán a medio o largo plazo como el factor de sostenibilidad. ${ }^{11}$ Aunque todos estos cambios son importantes, en este trabajo estamos interesados en las reformas que hayan afectado de forma distinta en función del sexo. ${ }^{12}$

Actualmente, el sistema de la Seguridad Social no cuenta con sesgos explícitos a la hora de calcular las pensiones para hombres y mujeres. Sin embargo, las inequidades acumuladas durante la vida laboral y el reparto, muchas veces desigual, de las cargas familiares, puede provocar un efecto negativo de algunas medidas de las reformas que, en principio, deberían

\footnotetext{
${ }^{8}$ Se crea una cuenta ficticia para cada trabajador donde se van incorporando cotizaciones hasta el momento de la jubilación, durante toda su vida laboral. Se trata de un sistema de aportación o contribución definida (la pensión de jubilación dependerá del salario y la totalidad de la vida laboral) frente al actual sistema de prestación definida. Las cuentas nocionales cambiarían la forma de determinar la cuantía de la pensión, pero se basan también en el sistema de reparto (los trabajadores financian las pensiones).

9 Cada trabajador financia, de forma individual, su propia pensión mediante el ahorro personal.

${ }^{10}$ Que eleva la pensión si aumentan los ingresos del sistema, pero la reduce si crece el número de pensiones o la pensión media, si bien se establece un umbral de +0.25 por ciento como límite mínimo de revalorización y un máximo equivalente a la tasa anual de inflación prevista más 0.5 por ciento.

${ }_{11}$ El factor de sostenibilidad iba a entrar en vigor en 2019, aunque se ha pospuesto a 2023 (Ley 23/2013) y supone incluir la esperanza de vida en el cálculo de la pensión, que repercutirá de forma inversa.

${ }^{12}$ En los próximos años podrá hacerlo el complemento por maternidad a las pensiones, que entró en vigor en 2016.
} 
afectar por igual a ambos sexos. De este modo, Vara Miranda (2011) destaca unos componentes que afectan al cómputo de las pensiones que podrían tener efectos más perjudiciales sobre la retribución de la mujer que en la del hombre:

1. El periodo de carencia o número mínimo de años cotizados necesarios para tener acceso a una pensión contributiva;

2. El número de años e importes cotizados que se toman como referencia para calcular la base reguladora.

Con respecto al primero, cuanto mayor sea el número mínimo de años necesario para poder optar a una pensión contributiva, el impacto negativo sobre la mujer tenderá a ser mayor. La búsqueda de la conciliación laboral no siempre es posible y muchas mujeres deciden o se ven obligadas a interrumpir su vida laboral para poder atender a personas dependientes. Por ello, ampliar el número de años para poder acceder a una pensión contributiva, incrementaría la desigualdad entre sexos.

En lo referente al periodo laboral que se tiene en cuenta para calcular la pensión, Leitner (2001: 103) argumentó que, si es elevado, se dificulta el acceso a los individuos que trabajan de forma discontinua o cobran bajos ingresos, que son dos características frecuentes de las mujeres en el mercado laboral. No obstante, cabe plantear que su ampliación podría ser beneficiosa, pues las mayores disparidades salariales se suelen concentrar en grupos etarios cercanos a la edad de jubilación y, tomando periodos más extensos, se podría reducir la brecha en las pensiones de jubilación, aunque a costa de reducir su cuantía media.

Hasta ahora, las reformas llevadas a cabo en el sistema de pensiones no contravienen lo expuesto en el Pacto de Toledo (consolidar el modelo existente y hacerlo viable, mediante reformas). Sin embargo, cabe preguntarse si será posible mantener las pensiones contributivas de prestación definida con una tasa de sustitución (relación entre salario y pensión) tan elevada como la actual. Algunos expertos, como Rubio-Ramírez (2010) o Jiménez-Martín (2013), consideran que esta situación no será sostenible durante mucho tiempo y plantean dos posibles soluciones: reducir la tasa de sustitución o pasar de un sistema de reparto con prestación definida a uno con contribución definida (sistema de cuentas nocionales), como en el caso de Italia y Suecia. No obstante, según Samek Lodovici et al. (2016) el uso de esta última vía podría elevar la brecha de género en las pensiones, puesto que, al incrementar la relación entre todas las contribuciones realizadas durante la vida laboral y las retribuciones en forma de pensión 
durante la etapa de retiro, podría provocar que las inequidades del mercado laboral se trasladasen de un modo más intenso sobre las pensiones.

Sin embargo, no todas las reformas tienen efectos negativos sobre la mujer. Aunque a corto y medio plazo sí parece que pueda afectarle de forma más perjudicial, a largo plazo, muchas de las medidas que se están adoptando buscan incentivar la prolongación de la vida laboral. Es decir, estas reformas podrían provocar un estímulo positivo, si logran aumentar la participación de la mujer en el mercado laboral y reducen los alicientes para su retirada prematura, mejorando el comportamiento de la brecha salarial y, por tanto, de las pensiones.

Asimismo, Jiménez-Martín (2009) plantea la necesidad de acompañar estas reformas con políticas sociales que ayuden a la conciliación laboral y familiar, pues aún no se ha resuelto uno de los problemas de fondo que afectan a la brecha de las pensiones por razón de género. Para este autor, medidas como el teletrabajo o el establecimiento de guarderías cerca del puesto de trabajo, podrían tener efectos positivos; por un lado, el aumento de la natalidad, afectando a una de las variables causantes del problema de la sostenibilidad del sistema; y, por otro, el fomento de la participación de la mujer en el mercado de trabajo, ayudando a reducir las disparidades laborales entre sexos.

\section{Brecha de género en las pensiones}

Como se ha mencionado, las diferencias de las pensiones entre hombres y mujeres se consideran una consecuencia directa de la posición de desventaja de la mujer en el mercado laboral, así como de las reglas del propio sistema de pensiones. Sin embargo, este mismo diseño puede conseguir reducir las diferencias generadas en el mercado laboral, al igual que puede agrandarlas.

En España, el sistema público de pensiones cuenta en su mayoría con pensiones contributivas (alrededor de 95 por ciento son de este tipo), aunque también existen las de carácter no contributivo, ya sea para completar la cuantía de las primeras hasta alcanzar el mínimo establecido o bien para garantizar un mínimo de renta a personas en riesgo de exclusión social que cumplan determinadas condiciones. Por tanto, son las pensiones contributivas las que acaban nutriéndose de las diferencias originadas en el mercado laboral y, por lo tanto, a las que se dedica este análisis.

Para realizar el análisis empírico de este apartado utilizaremos las dos divisiones habituales del sistema de la Seguridad Social, que distingue las pensiones por regímenes de cotización y según el concepto o tipo de pres- 
tación. Comenzando por la primera clasificación, nos interesa evaluar las distintas prestaciones por género según el régimen de cotización a partir de los datos ofrecidos en la Tabla 4.

Tabla 4: Pensiones contributivas según el tipo de régimen en España, 2016

\begin{tabular}{|c|c|c|c|c|c|}
\hline \multirow[b]{3}{*}{ Regímenes } & \multicolumn{3}{|c|}{ Número de pensiones } & \multicolumn{2}{|c|}{ Pensión media } \\
\hline & \multicolumn{3}{|c|}{ Distribución (\%) } & \multirow{2}{*}{$\begin{array}{r}€ / \text { mes } \\
\text { Total }\end{array}$} & \multirow{2}{*}{$\begin{array}{r}\mathrm{M} / \mathrm{H} \\
(\%)\end{array}$} \\
\hline & Total & Hombres & Mujeres & & \\
\hline General & 71.0 & 73.9 & 68.3 & 1000 & 63.9 \\
\hline Autónomos & 20.6 & 19.6 & 21.6 & 629 & 72.1 \\
\hline Otros & 8.4 & 6.5 & 10.1 & 763 & 45.0 \\
\hline Total & 100.0 & 100.0 & 100.0 & 904 & 62.4 \\
\hline
\end{tabular}

Nota: En Otros se incluyen los regímenes especiales de trabajadores del mar y minería del carbón, entre otros.

Fuente: elaboración propia a partir de datos del Ministerio de Empleo y Seguridad Social.

Como se puede apreciar, el régimen general es el más extendido en ambos sexos, siendo 71 por ciento del total. Este régimen incluye a la mayoría de los trabajadores asalariados y es uno de los que proporciona las retribuciones mensuales más elevadas, mientras que los restantes regímenes son más específicos y atañen a situaciones profesionales determinadas, destacando entre ellos el régimen de autónomos con 20.6 por ciento del total para ambos sexos. ${ }^{13}$

En lo que concierne a la diferencia de retribuciones entre ambos sexos, globalmente la pensión media femenina es 37.6 por ciento inferior que la masculina, aunque la distancia es especialmente elevada en Otros y se reduce por debajo de 30 por ciento en autónomos. Este último resultado contrasta con el obtenido en el conjunto de la Unión Europea, donde la mayor brecha de género se da, precisamente, en las pensiones de autónomos. Por ello, según Bettio, Tinios y Betti (2013) la tendencia ascendente de los últimos años del empleo femenino por cuenta ajena ha contribuido a corregir esta brecha globalmente.

Como se ha indicado, las pensiones también pueden ser analizadas según el tipo (viudez, orfandad...). Si bien la distribución de las pensiones

13 Sólo se ofrece el año 2016 porque, siguiendo a Vara Miranda (2011), resulta difícil realizar un análisis temporal desagregado dados los frecuentes cambios de legislación que han integrado diversos regímenes especiales en otros. Por ejemplo, desde 2008 los trabajadores por cuenta propia del régimen especial agrario quedaron integrados en el de autónomos (Ley 18/2007). Asimismo, a partir de 2012 se ha incluido dentro del régimen general el especial de empleados del hogar (Ley 27/2011). 
por regímenes entre hombres y mujeres es similar (Tabla 4), atendiendo a la clasificación según concepto (Tabla 5) la composición por sexos es bastante diferente, sobre todo en el caso de las pensiones de jubilación y viudez. Así, en el año 2016, 45.2 por ciento de las pensiones femeninas son de viudez frente a 3.9 por ciento de las masculinas; en cambio, casi un 80 por ciento de los hombres se benefician de una pensión propia, la de jubilación, cuya cuantía es más voluminosa que la pensión de viudez, mientras que las mujeres tienen un peso similar en ambos tipos. Esta dispar situación podría explicar una parte de la brecha de género en las pensiones.

Tabla 5: Pensiones contributivas según el concepto en España, 2003 y 2016

\begin{tabular}{|c|c|c|c|c|c|}
\hline \multirow[t]{2}{*}{2003} & \multicolumn{3}{|c|}{ Número de pensiones $(\%)$} & \multicolumn{2}{|c|}{ Pensión media } \\
\hline & Total & Hombres & Mujeres & $€ /$ mes & $\mathrm{M} / \mathrm{H}(\%)$ \\
\hline Jubilación & 58.8 & 78.4 & 39.3 & 625 & 61.6 \\
\hline Viudez & 27.0 & 3.6 & 50.2 & 398 & 125.4 \\
\hline Inc. Permanente & 10.3 & 14.2 & 6.3 & 641 & 72.6 \\
\hline Orfandad & 3.4 & 3.5 & 3.4 & 233 & - \\
\hline Favor familiar & 0.5 & 0.2 & 0.8 & 300 & - \\
\hline \multirow[t]{2}{*}{ Total } & 100.0 & 100.0 & 100.0 & 550 & - \\
\hline & \multicolumn{3}{|c|}{ Valor absoluto (miles) } & \multicolumn{2}{|c|}{ Brecha de género } \\
\hline Total & 7,856 & 3,914 & 3,942 & & \\
\hline \multirow[t]{2}{*}{2016} & \multicolumn{3}{|c|}{ Número de pensiones $(\%)$} & \multicolumn{2}{|c|}{ Pensión media } \\
\hline & Total & Hombres & Mujeres & $€ /$ mes & $\mathrm{M} / \mathrm{H}(\%)$ \\
\hline Jubilación & 60.9 & 78.7 & 44.0 & 1.043 & 62.5 \\
\hline Viudez & 25.1 & 3.9 & 45.2 & 638 & 134.9 \\
\hline Inc. Permanente & 10.0 & 13.3 & 6.8 & 930 & 82.3 \\
\hline Orfandad & 3.6 & 3.9 & 3.4 & 375 & 100.1 \\
\hline Favor familiar & 0.4 & 0.2 & 0.6 & 526 & 119.9 \\
\hline \multirow[t]{2}{*}{ Total } & 100.0 & 100.0 & 100.0 & 904 & 62.4 \\
\hline & \multicolumn{3}{|c|}{ Valor absoluto (miles) } & \multicolumn{2}{|c|}{ Brecha de género } \\
\hline Total & 9,409 & 4,580 & 4,829 & & \\
\hline
\end{tabular}

Fuente: elaboración propia a partir de datos del Ministerio de Empleo y Seguridad Social.

Como puede apreciarse, en las pensiones por muerte y supervivencia (viudez, orfandad y favor familiar), que son las que ostentan las cuantías medias más reducidas, la mujer recibe una retribución superior al varón, 
mientras que en las de jubilación e incapacidad permanente ocurre lo contrario. Si bien puede calcularse la disparidad de género en las pensiones a partir de la cuantía media global que percibe uno y otro sexo, se ha considerado oportuno tener en cuenta, además, la proporción de hombres y mujeres, siguiendo la fórmula propuesta por Bettio, Tinios y Betti (2013):

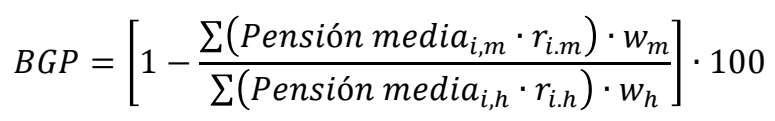

Siendo $r_{i, j}$ el peso de la pensión media según el concepto $i$ para cada sexo $j$ y $w_{j}$ la proporción de pensiones contributivas percibidas por hombres (subíndice h) y mujeres (subíndice m).

El resultado obtenido también figura en la Tabla 5 y refleja que, en media, la pensión femenina es 34.2 por ciento inferior a la masculina en 2016, brecha que en 2003 fue de 38.7 por ciento. Por tanto, aunque sigue existiendo un gran diferencial entre la pensión de hombres y mujeres, esta brecha se ha ido corrigiendo. Dinámica que puede explicarse por un aumento de las pensiones de jubilación femeninas en detrimento de las de viude $\mathrm{z}^{14}$ cuya cuantía media es inferior. Asimismo, el avance de la pensión media global y por sexos podría tener un efecto positivo sobre la reducción del riesgo de pobreza para edades avanzadas.

Por otra parte, considerando que el sistema de pensiones español proporciona una retribución cuya función es la de sustituir al salario, puede apreciarse que la diferencia de ingresos en 2016 se dobla una vez que finaliza la vida laboral, pasando de 14.9 a un 34.2 por ciento (Tabla 6), aunque hay que tener en cuenta que la brecha salarial se estima por hora de trabajo, mientras que en las pensiones es mensual. En cualquier caso, también estaría por encima de la brecha salarial anual entre sexos, cuyo promedio entre 2008 y 2015, así como en este último año es de 22.9 por ciento. ${ }^{15}$

Como se ha mencionado, la diferencia de ingresos en el mercado laboral es uno de los factores que afecta a la brecha de género en las pensiones $y$, además, hay que tener en cuenta que algunas mujeres apenas han trabajado o sólo lo han hecho de forma marginal.

No obstante, aunque las pensiones parece que agudizan la brecha de género, también se puede realizar otra interpretación: el sistema público de pensiones consigue reducir la desigualdad de ingresos entre hombres

\footnotetext{
${ }^{14} \mathrm{Ha}$ de tenerse en cuenta que algunas pensiones, como la de viudez, se pueden acumular con otras, lo que dificulta la estimación de la brecha.

15 Datos obtenidos de la Encuesta de Estructura Salarial del INE.
} 
y mujeres si la comparación se restringe a la población mayor de 65 años que continúa trabajando con la que pasa a ser pensionista; deducción que puede extraerse uniendo la información de la Tabla 6 con la ofrecida anteriormente en la Figura 8, dado que la diferencia de ingresos entre sexos pasa de 45.3 por ciento entre los asalariados de 65 o más años a 34.2 por ciento entre los pensionistas.

En definitiva, la Tabla 6 muestra una evolución favorable de ambas brechas de género, si bien cabe destacar que la brecha salarial de género se mantuvo estable en la primera etapa (2003-2007) de expansión económica, mientras que en el caso de las pensiones en dicho periodo se redujo casi un punto cada año, que es el retroceso experimentado en los nueve años siguientes.

Tabla 6: Brecha de género salarial y en las pensiones en España, 2003, 2007 y 2016 (porcentaje)

\begin{tabular}{lccc}
\hline & 2003 & 2007 & 2016 \\
\hline Brecha salarial & 18.0 & 18.1 & $14.9^{*}$ \\
Brecha en pensiones & 38.7 & 35.2 & 34.2 \\
\hline
\end{tabular}

* El dato utilizado es el último disponible publicado por Eurostat para 2015.

Fuente: elaboración propia a partir de las tablas 3 y 5 .

En la Unión Europea concurre una gran variedad de sistemas de pensiones que difieren de un país a otro, lo que puede plantear problemas a la hora de comparar la brecha de género entre países, dificultades que trataron de soslayar Bettio, Tinios y Betti (2013) y Betti et al. (2015) mediante una estimación que hemos actualizado con la última información disponible en la Figura 9.

En 2015, la brecha de género en las pensiones españolas (33.8 por ciento) ${ }^{16}$ se situó por debajo de la media de la Unión Europea (38.3 por ciento), mientras que países como Alemania, Austria o Reino Unido muestran las mayores disparidades, tal como ocurría con la brecha salarial (Tabla 3 ), correlación que puede explicarse porque la brecha entre sexos en las pensiones recoge los efectos acumulados de las inequidades laborales y, por tanto, si estas últimas son elevadas, una vez finalizada la vida laboral se trasladan a la etapa de retiro. Sin embargo, países como Estonia o la República Checa, consiguen reducir notablemente las disparidades, debido a que la brecha de género en las pensiones no sólo depende de la posición

16 Puede comprobarse que el valor de esta estimación está muy próximo al que hemos obtenido para 2016: 34.2 por ciento (Tabla 5). 
de desventaja de la mujer en el mercado de trabajo, sino que también está determinada por la propia regulación del sistema. En el caso estonio, una parte importante de la pensión no depende de la vida laboral, sino que existe un componente fijo que representa en torno a 40 por ciento de la cuantía de la retribución (Samek Lodovici et al., 2016). Otro hecho que conviene comentar es que la brecha de género en las pensiones apenas se altera entre 2014 y 2015 para la mayoría de los países, exceptuando el caso extremo de Rumanía, donde aumenta considerablemente, siendo un país con una reducida brecha salarial.

Figura 9: Brecha de género en las pensiones en la Unión Europea, 2014 y 2015 (porcentaje)

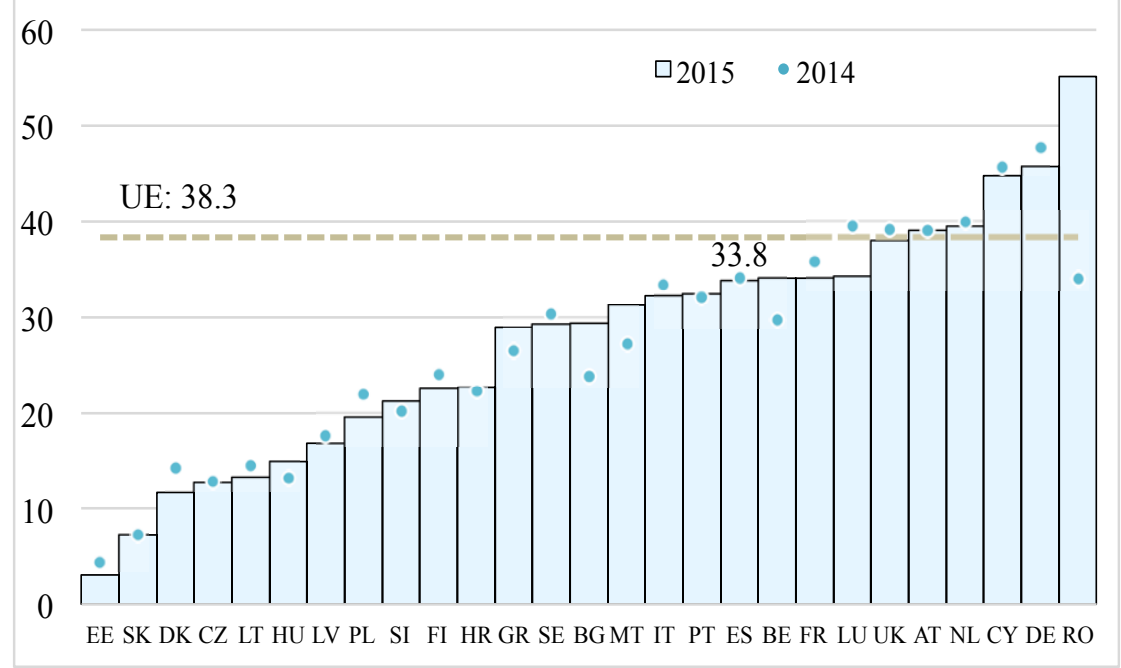

La identificación de los países se encuentra en el anexo. No hay datos disponibles para Croacia. Fuente: elaboración propia a partir de datos de la Comisión Europea.

Por tanto, parece que los sistemas de pensiones tienen la capacidad de amplificar o disminuir las inequidades producidas durante el transcurso de la vida laboral, pudiendo encontrar países cuyo sistema permite paliar estas disparidades. En todo caso, resulta necesario implementar otras políticas de conciliación laboral que permitan reducir las diferencias entre hombres y mujeres en el mercado de trabajo, es decir, tratar de resolver parte del origen de la brecha entre sexos en la etapa de retiro. La discriminación de un colectivo en función de su género no sólo es preocupante desde el punto de vista social, sino también desde la perspectiva económica. Por ello, desde distintos ámbitos se han propuesto estrategias para avanzar en 
materia de igualdad de género, encontrándose entre ellas Europa 2020 de la UE, que tiene entre sus objetivos el incremento de la participación femenina en la fuerza laboral y la reducción de la brecha salarial. Sin duda, su cumplimiento permitirá ir reduciendo las inequidades del mercado laboral que acaban afectando a la brecha de género en las pensiones.

Como se ha indicado, España ostenta una brecha de género en las pensiones inferior a la media de la UE en la actualidad, teniendo también una menor brecha salarial, a diferencia de lo que ocurría en 2003. Dado que en esta última brecha inciden, entre otros factores, la importancia de la jornada a tiempo parcial y la duración de la vida laboral, en la Tabla 7 se ha sintetizado la información de las tablas 1 y 2 , presentando la ratio entre mujeres y hombres de ambos indicadores.

Tabla 7: Ratio (mujeres/hombres) de la parcialidad en el empleo y de la duración de la vida laboral

\begin{tabular}{lrrrr}
\hline & \multicolumn{2}{c}{ Peso empleo parcial } & \multicolumn{2}{c}{ Duración vida laboral } \\
\hline & España & UE-28 & España & UE-28 \\
\hline 2003 & 6.4 & 4.7 & 0.691 & 0.819 \\
2007 & 5.7 & 4.4 & 0.761 & 0.830 \\
$2016^{*}$ & 3.2 & 3.6 & 0.874 & 0.865 \\
\hline
\end{tabular}

* 2015 en la duración de la vida laboral.

Fuente: elaboración propia a partir de las tablas 1 y 2 .

Como puede apreciarse, la proporción de empleadas a tiempo parcial sobre la tasa de parcialidad masculina era 6.4 veces superior en España en 2003, muy por encima del resultado de la UE, donde se aproximó al quíntuplo. Sin embargo, si bien la jornada a tiempo parcial ha ganado peso en ambos colectivos (véase Tabla 1), lo ha hecho de forma más intensa entre los hombres, especialmente en España. Así, aunque la parcialidad le afecta con mucha más intensidad al colectivo femenino, la distancia se ha reducido hasta menos de cuatro veces, logrando España mayor cercanía que la UE en 2016. Algo similar ocurre si se compara la duración de la vida laboral, dado que, como puede apreciarse, en 2003 era 30.9 por ciento inferior en las mujeres que en los hombres (18.1 por ciento en la UE), mientras que al final del periodo esta distancia se ha reducido a 12.6 por ciento (13.5 por ciento en la UE). Esta convergencia en dos importantes indicadores laborales atendiendo al género guarda correspondencia con el hecho de que la brecha salarial fuese dos puntos superior en España que en la UE en 2003 y 1.4 puntos inferior en 2015. Por tanto, de mantenerse esta 
tendencia, ceteris paribus la brecha de género en las pensiones continuará estando por debajo en España.

\section{Implicaciones sobre la calidad de vida}

La calidad de vida es un aspecto esencial, pues de ella depende en parte el bienestar de las personas y, por tanto, el de la sociedad. Los sistemas de pensiones deben de ser capaces de asegurar que, una vez finalizada la etapa laboral, las personas de avanzada edad puedan seguir disfrutando de un nivel de vida digno. Asimismo, la desigualdad entre sexos, tanto en el periodo activo como en el de retiro, podría estar afectando a la calidad de vida y, por tanto, cabe plantear en qué medida estas disparidades pueden elevar el riesgo de pobreza en la mujer.

Una medida que puede utilizarse para cuantificar esta contingencia es la tasa de riesgo de pobreza y/o exclusión social, conocida como indicador $\mathrm{AROPE}^{17}$ por las siglas en inglés (At Risk of Poverty and/or Exclusion). En él se incluyen las personas de 65 años o más de bajos ingresos y/o que sufren privación material severa y/o que viven en hogares de baja intensidad laboral (Samek Lodovici et al., 2016). La Figura 10 da cuenta de esta tasa para los pensionistas por sexo en 2015.

De acuerdo con este indicador, las mujeres pensionistas tienen un mayor riesgo de caer en la pobreza y/o exclusión social que los hombres en la UE (15.1 por ciento frente a 11.6 por ciento en 2015). Por el contrario, España, además de encontrarse por debajo de la media, son los hombres quienes presentan un valor más elevado de este indicador ( 8.8 por ciento y 11 por ciento en la mujer), algo similar a lo que ocurre en Malta, Bélgica o Italia. Así, aunque cabría esperar que exista una relación positiva entre la brecha de género en las pensiones y el riesgo mayor de pobreza para la mujer en comparación con el hombre, la evidencia no parece confirmarla. Bettio, Tinios y Betti (2013) pusieron de manifiesto esta paradoja y consideran que puede deberse al distinto ámbito representado en cada concepto: mientras que la brecha de las pensiones está definida de forma individual, la pobreza se determina en el hogar.

A semejanza del análisis efectuado por grupos etarios en el caso de la brecha salarial (Figura 8), en la Figura 11 se ha cuantificado el indicador AROPE por intervalos de edad, representación que pone de manifiesto un hecho relevante: hasta alcanzar la edad media de maternidad (EMM de 32 años en 2015), las mujeres tienen un menor riesgo de pobreza que los

17 Un interesante análisis metodológico sobre este indicador y su aplicación a las regiones españolas se encuentra en Faura, Lafuente y García (2016). 
hombres, mientras que en los grupos de edad posteriores ocurre lo contrario, especialmente a partir de 65 años. Algo similar ocurría con la brecha salarial por sexos, que se ampliaba abruptamente para grupos superiores a la EMM y alcanzaba su punto álgido en el grupo de edades avanzadas. Sin embargo, el sistema de pensiones consigue, por una parte, frenar el avance de la diferencia salarial al elevar la edad y, por tanto, reducir el riesgo de pobreza para ambos sexos durante la etapa de retiro.

Figura 10: Tasa de riesgo de pobreza y/o exclusión social (Indicador AROPE) para pensionistas en la UE (porcentaje), 2015

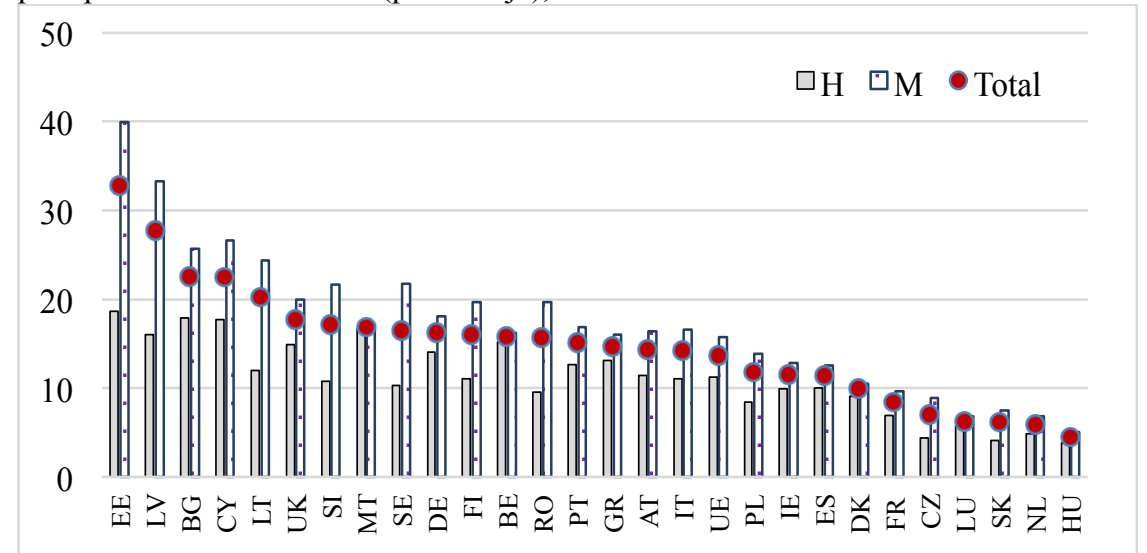

La identificación de los países se encuentra en el anexo. No hay datos disponibles para Croacia. Fuente: elaboración propia a partir de Eurostat, Stadistics on Income and Living Conditions (SILC).

Figura 11: Evolución de la tasa de riesgo de pobreza y/o exclusión social (AROPE) por grupos etarios y sexo, 2015 (porcentaje)

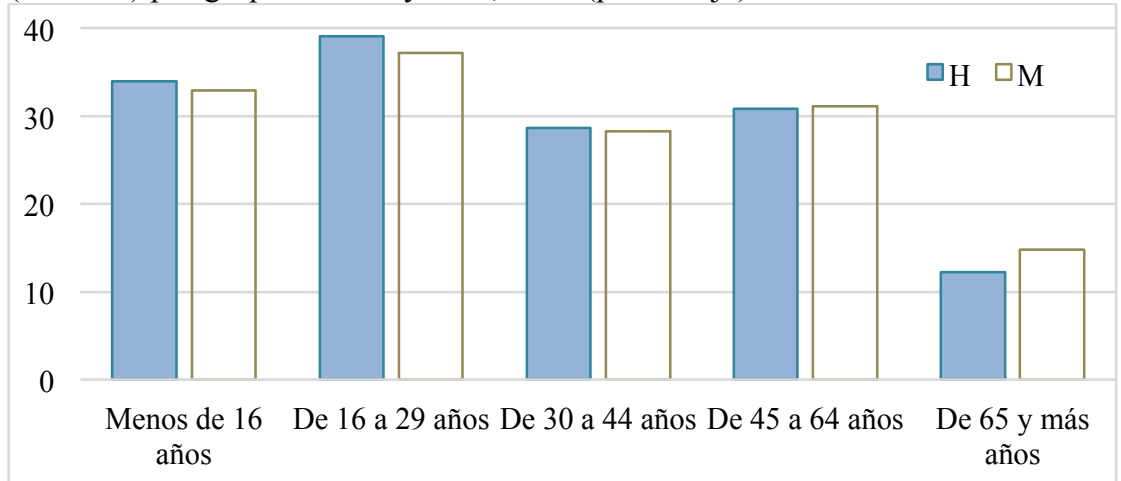

Fuente: elaboración propia a partir de Eurostat, Stadistics on Income and Living Conditions (SILC). 


\section{Conclusiones}

En este trabajo se ha intentado mostrar cómo las inequidades acumuladas por la mujer en el mercado laboral acaban reflejándose en un diferencial de ingresos en el periodo de retiro, así como las posibles implicaciones de esto sobre la calidad de vida.

La pensión es una retribución monetaria que intenta asegurar un nivel de vida digno una vez finalizada la vida laboral. No obstante, la acumulación de inequidades que existen a lo largo de la trayectoria laboral acaba traduciéndose en una disparidad: la brecha de género en las pensiones. Entre las causas principales que la generan destacan, en primer lugar, la menor participación de la mujer en el mercado laboral (existe una diferencia de 11.5 puntos porcentuales entre las tasas de actividad de hombres y mujeres en 2015) y, en segundo lugar, el uso más intenso de la jornada a tiempo parcial, así como el mayor grado de interrupciones de la vida laboral, muchas veces dándola por finalizada prematuramente (se ha estimado que la mujer española trabaja 22 años menos que el hombre, lo que afectará a la brecha de género en las pensiones). La menor implicación de la mujer en el mercado laboral se acaba traduciendo en un diferencial de ingresos entre sexos, tanto presentes (15 por ciento de brecha salarial) como futuros (34.2 por ciento en las pensiones).

Cabe destacar que la brecha actual de género en las pensiones españolas es inferior a la media de la UE, teniendo también una menor brecha salarial, lo contrario que ocurría en 2003. Esta situación está vinculada con la convergencia entre hombres y mujeres que se ha producido en dos indicadores laborales: la importancia de la jornada a tiempo parcial y la duración de la vida laboral. De mantenerse esta tendencia, cabe esperar que la brecha de género en las pensiones continúe siendo menor en España que en la UE.

Por otra parte, dentro del ámbito de las pensiones existen otros factores que pueden ayudar a reducir esta disparidad. Así, un sistema de reparto como el español tiene la capacidad de redistribuir la riqueza, lo que permite que actúe como un filtro, aliviando así la desigualdad de ingresos y, en consecuencia, afectará positivamente a la calidad de vida para personas de edad avanzada. Una de las tendencias que apoyan esto es la ralentización del avance de la brecha salarial de un grupo etario a otro. Según se pasa a edades avanzadas, esta brecha salarial aumenta de 5.7 por ciento acabando en 45.3 por ciento.

A pesar de esto, si bien el sistema de pensiones puede ayudar a reducir estas diferencias de ingresos, también puede incrementarlas. Los proble- 
mas de sostenibilidad financiera han promovido muchas reformas, parte de las cuales han podido afectar de forma más intensa a la mujer. El aumento del periodo de carencia o número mínimo de años cotizados necesarios para tener acceso a una pensión contributiva, así como los importes cotizados tomados como referencia para calcular la base reguladora son algunas de ellas. Asimismo, el posible avance hacia sistemas de capitalización o de reparto y cuentas nocionales acabarían teniendo un impacto negativo sobre la mujer, pues la relación entre la pensión otorgada y las contribuciones realizadas sería más estrecha. No obstante, aunque pueda parecer que en un principio van a tener un efecto negativo sobre la pensión femenina, a medio o largo plazo los efectos sobre la implicación de la mujer en el mercado laboral podrían ser beneficiosos, aliviando la brecha de género en las pensiones.

\section{REFERENCIAS BIBLIOGRÁFICAS}

Arcanjo, Manuela, 2019, "Retirement Pension Reforms in Six European Social Insurance Schemes between 2000 and 2017: More Financial Sustainability and More Gender Inequality?”, in Social Policy and Society, 18 (4), pp. 501-515.

Ayuso, Mercedes y Chuliá, Elisa, 2018, ¿Hacia la progresiva reducción de la brecha de género en las pensiones contributivas?, Documento de trabajo 22, Instituto BBVA, Madrid.

Betti et al., 2015, "Gender Gaps in Pensions in Europe", en Betti, Gianni; Bettio, Francesca; Georgiadis, Thomas y Tinios, Platon, Unequal Ageing in Europe. Women's Independence and Pensions, Palgrave Macmillan US, New York, pp. $35-54$.

Bettio, Francesca, Tinios, Platon y Betti, Gianni, 2013, The Gender Gap in Pensions in the EU, European Commission, Directorate-General for Justice, Publications Office of the European Union, Luxembourg.

Boletín Oficial de las Cortes Generales, 1995, "Informe de la ponencia para el análisis de los problemas estructurales del sistema de la Seguridad Social y de las principales reformas que deberán acometerse", Boletín Oficial de las Cortes Generales, núm. 134, 12/04/1995, http://www.in-formacioncgt.info/legislacion/ acuerdos-marco/pacto-toledo.pdf

Castro Martín, Teresa, 2010, “¿Puede la inmigración frenar el envejecimiento de la población española?", Análisis del Real Instituto Elcano, ARI, núm. 10, http:// www.realinstitutoelcano.org/publicaciones/ari

Comisión Europea, 2014, Cómo combatir la brecha salarial entre hombres y mujeres en la Unión Europea, Dirección General de Justicia, Oficina de publicaciones de la UE, Luxemburgo. 
Del Campo, Salustiano y Rodríguez-Brioso, María del Mar, 2002, "La gran transformación de la familia española durante la segunda mitad del siglo XX", en REIS-Revista Española de Investigaciones Sociológicas, No 100/2, pp. 103-165.

Devesa, José Enrique, Meneu, Robert y Devesa, Mar, 2010, La pensión de jubilación: reformulación de la tasa de sustitución para la mejora de la equidad y sostenibilidad del sistema de la Seguridad Social. Resultados basados en la MCVL, Secretaría de Estado de Seguridad Social, Ministerio de Trabajo e Inmigración.

Dumont, Gérard-François, 2007, "El envejecimiento de las poblaciones en Europa o el invierno demográfico", en Debats, núm. 96, pp. 15-23.

Elborgh-Woytek, Katrin et al., 2013, Las mujeres, el trabajo y la economía: beneficios macroeconómicos de la equidad de género, Fondo Monetario Internacional, Documento de Análisis del Personal Técnico, Departamento de Estrategia, Políticas y Evaluación y Departamento de Finanzas Públicas.

Faura, Úrsula, Lafuente, Matilde y García, Olga, 2016, "Riesgo de pobreza o exclusión social: evolución durante la crisis y perspectiva territorial", en Reis: Revista Española de Investigaciones Sociológicas, 156, 59-76.

Hernández, Pablo, Jimeno, Juan Francisco y Ramos, Roberto, 2017, Sistema público de pensiones en España: situación actual, retos y alternativas de reforma, Documentos Ocasionales, núm. 1701, Banco de España.

INE, 2017, Indicadores demográficos básicos, Metodología, Instituto Nacional de Estadística, INE.

Jiménez-Martín, Sergi, 2009, El diferente impacto del género en el sistema de pensiones español, Secretaría de Estado de Seguridad Social, Ministerio de Trabajo e Inmigración.

Jiménez-Martín, Sergi, 2013, "La reforma del sistema de pensiones: el factor de sostenibilidad", en Nada es gratis, 26-02-2013, http://nadaesgratis.es/sergi-jimenez

Jímenez-Ridruejo, Zenón, Borondo, Carlos, López, Julio, Lorenzo, Carmen y Rodríguez, Carmen, 2009, "El efecto de la inmigración en la sostenibilidad a largo plazo del sistema de pensiones en España", en Hacienda Pública Española, núm. 188, pp. 73-122.

Leitner, Sigrid, 2001, "Sex and gender discrimination within EU pension systems", in Journal of European Social Policy, num. 11/2, pp. 99-115.

Lorenzo Carrascosa, Laura, 2004, Consecuencias del envejecimiento de la población: el futuro de las pensiones, Instituto Nacional de Estadística, INE, http:// www.ine.es/daco/daco42/sociales/infosoc_envej.pdf

Martín López, Carolina, 2000, "La mujer en el mercado de trabajo", en Anales de Economía Aplicada, XIV Reunión ASEPELT, Oviedo, 22 y 23 de Junio.

Millán-Vázquez, María Genoveva, Santos, Manuela del Pilar y Pérez, Leonor María, 2015, "Análisis del mercado laboral femenino en España: evolución y factores 
socioeconómicos determinantes del empleo", en Papeles de población, núm. 84, vol. 21, pp. 197-225.

Moreno Moreno, María del Carmen, 1997, Análisis económico del sistema de pensiones públicas, Documentos de trabajo de la Facultad de Ciencias Económicas y Empresariales, núm. 13, Universidad Complutense de Madrid.

Pérez Díaz, Julio, 2003, "Feminización de la vejez y Estado del Bienestar en España”, en REIS-Revista Española de Investigaciones Sociológicas, núm. 104/03, pp. 91-121.

Pérez Díaz, Julio, 2010, “El envejecimiento de la población española”, en Investigación y Ciencia, núm. 410, pp. 34-42.

Rubio Ramírez, Juan, 2010, Pensiones de jubilación ¿para qué, cómo y cuáles?, Recuperado el 10/05/2017, Nada es gratis: http://nadaesgratis.es/rubio-ramirez

Samek Lodovici, Manuela, Drufuca, Serena, Patrizio, Monica y Pesce, Flavia, 2016, The gender pension gap: differences between mothers and women without children, European Parliament, Policy Department for Citizens' Rights and Constitutional Affairs, Brussels, http://www.europarl.europa.eu/supporting-analyses

Sarasola, Maru, Sarasola, Sebastián y García, Estíbaliz, 2012, Brecha salarial: causas e indicadores, EMAKUNDE-Instituto Vasco de la Mujer, Vitoria-Gasteiz.

Serrano, Lorenzo y Soler, Ángel, 2015, La formación y el empleo de los jóvenes españoles: trayectoria reciente y escenarios futuros, Fundación BBVA, Bilbao.

Serrano-Martínez, José María y García-Marín, Ramón, 2013, "Regresión demográfica en España: crisis económica y cambio de ciclo migratorio", en Papeles de Población, núm. 76, vol. 19, pp. 89-128.

United Nations, 2015, World Population Ageing 2015, Report, Department of Economic and Social Affairs, United Nations, New York.

Valenzuela, Hugo, Reygadas, Luis y Cruces, Francisco, 2015, “Mi trabajo es mi vida. La incrustación de los mundos de la vida y del trabajo en empresas españolas”, en Revista Española de Investigaciones Sociológicas, 150, pp. 191-210.

Vara Miranda, María Jesús, 2011, "La desigualdad de género en el sistema público de pensiones: el caso de España”, en Información Comercial Española, núm. 859, pp. 119-139.

Vara Miranda, María Jesús, 2013, "Gender inequality in the Spanish public pension system”, en Feminist Economics, 19 (4), pp. 136-159.

Vicente, Ana María y Martínez, Timoteo, 2010, Cambios en el mercado laboral español. La incorporación de la mujer al mercado laboral: factores determinantes a nivel geográfico, profesional y por actividades en el Sistema de la Seguridad Social, Secretaría de Estado de Seguridad Social, Ministerio de Trabajo e Inmigración, Madrid. 


\section{RESUMEN CURRICULAR DE LOS AUTORES}

\section{María López Martínez}

Doctora en Ciencias Económicas y Empresariales (Económicas) por la Universidad de Murcia (1994). Premio Extraordinario de Licenciatura. Es profesora titular de la misma universidad, en el Departamento de Economía Aplicada. Ha sido profesora visitante en el Centre Regional de la Productivité et des Études Économiques de Montpellier (Francia). Publicaciones recientes (coautora): "Estructura interindustrial y desarrollo económico. Un análisis desde las perspectivas de redes e input-output", en El Trimestre Económico, 2016; "El fracaso escolar en España y sus regiones: disparidades territoriales", en Revista de Estudios Regionales, 2016; "Estimación del bienestar socioeconómico de las comarcas de la región de Murcia”, en Revista de Estudios Regionales, 2018; "Análisis de la segregación ocupacional por género en España y la Unión Europea (2002-2017)”, en Revista Prisma Social, 2019; "Desigualdad de género y convergencia en los países de la UE-28 (2005-2015)", en Revista de Economía Mundial, 2019.

Dirección electrónica: marlomar@um.es

Registro ORCID: https:/orcid.org/0000-0002-6363-2852

\section{Blas Ángel Marín López}

Graduado en Economía por la Universidad de Murcia. Alumno interno del Departamento de Economía Aplicada en dicha Universidad durante dos cursos académicos. Ha terminado el Máster Universitario en Economía Cuantitativa (QED) en la Universidad de Alicante, realizando en la actualidad el Doctorado en Economía por dicha Universidad. Es investigador predoctoral en el Departamento de Fundamentos del Análisis Económico de la Universidad de Alicante.

Dirección electrónica: bm31@alu.ua.es

\section{Anexo}

\begin{tabular}{|l|c|l|c|l|c|l|c|}
\hline \multicolumn{2}{|l|}{ Anexo 1: Abreviaturas de los países de la UE-28 } \\
\hline Austria & AT & Estonia & EE & Irlanda & IE & Polonia & PL \\
\hline Bélgica & BE & España & ES & Italia & IT & Portugal & PT \\
\hline Bulgaria & BG & Finlandia & FI & Lituania & LT & Rumania & RO \\
\hline Chipre & CY & Francia & FR & Luxemburgo & LU & Suecia & SE \\
\hline Rep. Checa & CZ & Grecia & GR & Letonia & LV & Eslovenia & SI \\
\hline Alemania & DE & Croacia & HR & Malta & MT & Eslovaquia & SK \\
\hline Dinamarca & DK & Hungría & HU & P. Bajos & NL & Reino Unido & UK \\
\hline
\end{tabular}

Artículo recibido el 4 de septiembre de 2017 y aprobado el 19 de marzo de 2019. 